\title{
Sketch of the History of Mathematics in Scotland to the end of the I8th Century: Part II.
}

\author{
By Professor G. A. Gibson.
}

(Read 7th August 1926. Received 4th January 1927.)

The centre of interest now shifts from St Andrews and Edinburgh to Glasgow. The troubles that afflicted Scotland during the 17th Century bore heavily on Glasgow University and more particularly on the position of Mathematics in the University; but in 1691 a distinct Professorship of Mathematics was founded, and from that date the old system of Regents disappeared from Glasgow so far as Mathematics was concerned. The first occupant of the Chair was George Sinclair, who is now chiefly remembered by the controversy in which James Gregory held up Sinclair's Treatise Ars nova et magna to ridicule. It is not fair however to take Gregory's pamphlet as a final estimate of Sinclair's contributions to science; Sinclair laid himself open to attack, but he rendered great service to the mining industry of Scotland and deserves the gratitude of posterity in spite of his many eccentricities. His contributions to mathematics however are of no importance, but during his tenure of the Chair the number of students grew rapidly and the new professorship made a good start.

George Sinclair was succeeded in 1699 by Dr Robert Sinclair of whose work or attainments ${ }^{1}$ I can say nothing. In 1711 Robert Simson was elected, and we must give more attention to him as he left an enduring mark on the development of mathematics in Scotland.

Robert Simson was born at Kirtonhill, West Kilbride, Ayrshire, in 1687. When he entered Glasgow University Trail in his life of Simson states that " at this time, from temporary circumstances, it happened that no Mathematical Lectures were given in the College; but young Simson's inquisitive mind, from some fortunate incident having been directed to Geometry, he soon perceived the study of that science to be congenial to his taste and capacity. This taste, however, from an apprehension that it might obstruct his application

${ }^{1}$ In 1704 Sinclair was intrusted by the Faculty with the teaching of Hebrew. 
to subjects more connected with the study of theology, was anxiously discouraged by his father, though it would seem with little effect. Having procured a copy of Euclid's Elements, with the aid only of a few preliminary explanations from some more advanced students, he entered on the study of that oldest and best introduction to Mathematics. In a short time he read and understood the first six with the eleventh and twelfth books; and being delighted with the simplicity of language and accuracy of reasoning in Euclid, notwithstanding the discouragements he met with, he persevered in his Mathematical pursuits; and by his progress in the more difficult branches he laid the foundation of his future eminence." As Trail was a pupil and, later, a close personal friend of Simson, I think we may accept the above statement as a true account of Simson's mathematical education. In any case Simson had acquired a reputation, for in 1710 he was offered the Chair of Mathematics. He asked however to be allowed to spend at least one year in London for the purposes of study; the Faculty granted his request, kept the position open, and in 1711 definitely appointed him Professor of Mathematics. He retired in 1761 and died in 1768. In 1746 he received the degree of M.D. from the University of St Andrews.

Simson's University course extended over two sessions of seven months each, and seems to have preserved the same general plan throughout his professorship. The fullest description of it that I have met with is by Professor Robison who was a student under him. Robison states (Encycl. Brit., 3rd Ed., vol. 17, pp. 504-509): he "made use of Theodosius as an introduction to spherical trigonometry. In the higher geometry he prelected from his own Conics, and he gave a small specimen of the linear problems of the ancients by explaining the properties sometimes of the conchoid, sometimes of the cissoid, with their application to the solution of such problems. In the more advanced class he was accustomed to give Napier's mode of conceiving logarithms, i.e. quantities as generated by motion and Mr Cotes's view of them as the sums of ratiunculae; and to demonstrate Newton's lemmas concerning the limits of ratios and then to give the elements of the fluxionary calculus; and to finish off his course with a select set of propositions in Optics, gnomonics and central forces. His method of teaching was simple and perspicuous, his elocution clear, and his manner easy and impressive. He had the respect, and still more the affection, of his scholars." Both Trail and Robison note his readiness to encourage any students who showed special ability and the trouble he would take in guiding them to 
authorities. Robison adds that he treated the trigonometrical functions as ratios before Euler had made the method popular.

Simson is known almost solely as an exponent of the Greek geometry, but $I$ think it is worth noticing that when he was still a young man he showed a full command of one branch of analysis. In a letter to Dr Jurin, of date 1st February 1723, he sent proofs of the addition formula for the tangent and deduced the expression (for $a>1$ )

$$
\tan ^{-1}\left(\frac{1}{a}\right)=2^{n} \tan ^{-1}\left(\frac{1}{2^{\prime \prime} a}\right)-\sum_{k=1}^{n} 2^{k-1} \tan ^{-1}\left\{\frac{1}{2^{k-1} a\left[2^{* k} a^{2}+3\right.}\right\}
$$

from this he deduced several series for $\pi$, among them the series known as Machin's Series. Simson did not claim any originality for his work, but Jurin's letter in reply shows that he had given much more general results than were then known in Machin's circle. But analysis of this kind did not really interest Simson, and it is for his devotion to the ancient geometry that he is specially memorable.

Though not the first to be published his best known work is the translation of Euclid (Books $i-v i, x i$, xii) from the edition of Commandine. This was published in 1756, separate editions in Latin and in English being issued; a second edition in English, along with a translation of Euclid's Data, appeared in 1762. It is perhaps within the mark to say that every English edition of Euclid till near the close of last century (with the exception of Williamson's) was not merely influenced by Simson's work but was in all essentials based on Simson's text and not on the Greek text. For good or for ill it was Simson's conception of Euclid that prevailed in this country till our own days. If we are to form a fair judgment we should consider not merely what has been done since Simson's time for the study of elementary geometry but, quite as much, what was the state of the geometrical textbook before the issue of Simson's Euclid. Judging from my own reading $I$ am of opinion that the welcome given to Simson's text was to a large extent due to the very unsatisfactory character of the texts then current in this country-in England as well as in Scotland. It is a very striking fact not merely that Euclid became predominant but that one particular edition ousted all rivals for so long. Simson had no really good original to work upon, and he was in no real sense of the word a competent textual critic; but he had a clear conception of the general trend of Euclid's development, and he stuck to that with almost fanatical tenacity. He was simply 
steeped in the ancient geometry and one should be very sure of one's ground before questioning any deliberate judgment of Simson's on the facts of any Greek textbook.

The only other textbook published by Simson was his Conic Sections. Sectionum Conicarum Libri Quinque (Edinburgh, 1735); a second, improved and enlarged, edition appeared in 1750. The book was designed to stem the tide that had begun to set in in favour of Analytical or Algebraic Geometry (on the lines of de l'Hôpital's wellknown work); though it was based on Apollonius the cone was not used in defining the conic. For the parabola the focus and directrix property, for the ellipse and the hyperbola the constancy of the sum and the difference of the focal radii to a point are used to define the curves. For many years English translations of the first three books were in use in many of the Scotch schools but it is now seldom met with. Of course all the proofs are strictly Euclidean and very little is taken for granted; no important property is shoved into a Corollary. But the book is quite a good exposition and worthy of its author; it is the first textbook which contains the theorems of Desargues and Pascal.

To the study of Greek geometry Simson may almost be said to have dedicated his life, and he found ample scope for his ingenuity in his effort to recover some of the more important of the treatises of Euclid and Apollonius that had been lost but whose contents had been to a certain extent described by Pappus. The text of Pappus' Collection was itself in a very unsatisfactory state so that the opportunities for conjecture were endless. Though $I$ have at various intervals spent a considerable time in the study of these lost treatises I cannot profess to have mastered the subject, or indeed to have reached any decided conclusion on the most debateable points, so that I must content myself with little more than a list of titles.

In 1749 he published his Restitution of the Loci Plani of Apollonius. In this case he had predecessors in Fermat and Schooten, but he added considerably to what they had given. Traill was neither unprejudiced nor very critical, but he had a competent knowledge of Greek geometry and was thoroughly familiar with Simson's work, and I quote his estimate of the edition:-_" Such is the elegance of method and the ingenious contrivance of demonstration in this work that he has truly exhibited a copy, or at least very nearly a copy, of the work of Apollonius, that little regret need be had for the loss of the original." We need not indorse this eulogium in its entirety but it is not altogether wide of the mark. 
Simson's Opera Reliqua, published in 1776 from his MSS under the editorship of Professor Clow (Professor of Logic in Glasgow University), contains besides two short tracts on Logarithms and Limits the restoration of Apollonius's Determinate Section and Euclid's Porisms. In recent times the geometry developed in the Determinate Section has often been represented as in many respects an equivalent of the modern theory of Involution, though it is not at all from that standpoint that Simson considered it. There are however many propositions that can be readily adapted to the geometry of involution.

The mystery of Euclid's Porisms however seems to have fascinated Simson, and from the very early days of his professorship he seemed to brood over it. Till he produced his article in the Philosophical Transactions in 1723 there had been no elucidation of the mystery that had baffled every inquirer, and even then there was only an approach to a solution, not the solution itself. Simson worked at the subject to the day of his death and was very unwilling to publish the MS which he had completed, though he left it in such a state that it could be sent to the press. Whether he has succeeded in solving the mystery of the porisms completely is still a moot point. Chasles, the next in importance of those who have thoroughly investigated the subject, agrees in the main with Simson's conceptions, but developes certain views of his own. Heiberg is less enthusiastic, though I do not attach quite the same weight to Heiberg's views in this connection as in other fields in which he has rendered such great service to Greek geometry. I cannot here enter at all into the matter; the literature of the subject is considerable, and I may refer to Heath's Greek Mathematics, Vol. I, pp. 431-438, for a short description of the more important conceptions of a porism and for references to the literature.

Simson may justly be described as a "great geometer"; but while each man must be allowed to follow his bent I agree with one of his distinguished pupils that it is a matter of regret that he devoted himself so exclusively to the restoration of the lost books of the ancients and took such a slight interest in the development of the new analysis. He had a competent knowledge of fluxions but he never really set himself to master algebraical analysis, and he held views that were completely antiquated on the nature and possibilities of algebra and of algebraic geometry. It is much to be regretted that he did not apply his profound knowledge of the Aristotelean 
logic to the somewhat crude reasonings of the founders of the modern algebra; had he devoted to this branch of mathematics a tithe of the labour he expended on the restoration of mutilated texts he would probably have had a more beneficial influence on the development of mathematics in Scotland.

In the first group of Snell Exhibitioners sent up in 1699 by Glasgow College to Balliol College, Oxford, one was a GregoryCharles Gregory (born 1681), fourth son of David Gregory of Kinairdy, and brother of David Gregory who had succeeded his uncle James Gregory as Professor of Mathematics at Edinburgh. Charles was Professor of Mathematics in St Andrews from 1707 to 1739 when he resigned his chair in favour of his son David, though he survived till 1754. Neither Charles nor David made any contribution to mathematics that requires mention. But the Snell Exhibition was of essential assistance in the promotion of mathematics when it was conferred on James Stirling who matriculated at Balliol on 18th January $17 \frac{1}{1} \frac{0}{1}$.

Mr Tweedie in his book James Stirling: a Sketch of his Life and Works along with his Scientific Correspondence (Oxford: 1922) has dealt so fully and accurately with Stirling's position as a mathematician that I can do nothing more than summarise his statements. I should like however to remark that Mr Tweedie's book is a piece of genuine historical research on a totally different level from that of much more pretentious volumes.

James Stirling was born at Garden in Stirlingshire in 1692 of a family noted for its Royalist-that is, Jacobite-sympathies. It is probable, though there is no documentary evidence for the supposition, that he studied at Glasgow, and his nomination to the Snell Exhibition may have been made by Balliol College to which the right of nomination fell if Glasgow College did not within a certain period send up a scholar or scholars. Stirling's Jacobite sympathies were a source of trouble, but he evidently made a name for himself as a competent mathematician and the story that he was expelled from the University because of his Jacobitism is, in Mr Tweedie's opinion, without foundation. In 1717, on the invitation of Nicolas Tron, the Venetian Ambassador at the English Court to whom he had dedicated his Lineae Tertii Ordinis Neutonianae, he went to Italy in the belief that he would be appointed to a professorship of mathematics in one of the Universities of the Venetian Republic (Padua seems to have been the only "one"). Stirling however was an "Anglican," and, as 
such, was not acceptable in a Roman Catholic State, so that the proposals for a University Chair fell to the ground. For some time he was financially embarassed as the Stirling family had suffered for their adhesion to the Stewarts, but the kindly and generous help of Newton brought him relief. It is a pity that so little is known of Stirling's doings in Italy or of the men whom he met; he was certainly in touch with the Bernoullis to the extent that he met Nicholas, as is shown by Stirling's letter to Newton. The connection with Italy is preserved by the epithet "The Venetian" which is applied to him in the Family History of the Stirlings.

On returning from Venice to England he settled in London and was for some years connected with an Academy in Little Tower Street; to this address many letters were sent to him by foreign mathematicians. Mr Tweedie says that "from 1730 onwards Stirling's life in London must have been one of considerable comfort as his 'affairs' became prosperous, while he was a familiar figure at the Royal Society where his opinions carried weight." Still the Academy at Little Tower Street was not at all a satisfactory place for a man of Stirling's abilities, and in 1735 a change came that meant a break with systematic mathematical studies. He was in that year appointed Manager of the Leadhills Mines, and his eminently successful reorganisation and administration of the Mines gave decisive proof that there is no necessary incompatibility between mathematical genius and commercial efficiency. The heavy responsibilities of the managership left little leisure for mathematics, and though his merits as a mathematician were recognised in more ways than one his contributions to mathematics may be said to end with his entry on the serious work at Leadhills. He resigned his membership of the Royal Society in 1754; in 1770 he died and was buried in the Greyfriars' Churchyard.

Stirling made important contributions to mathematics in two different fields (i) in the theory of Higher Plane Curves, and (ii) in the theory of Series. The main features of the Lineae... Neutonianae are well and briefly summarised by Brill and Noether in their "Report on the Development of the Theory of Algebraic Functions" (pp. 128, 129) though they are not quite accurate in their reference to Stirling's examples on his form of Taylor's Theorem. The treatise is, in their judgment, excellent in the treatment of the practical tracing of curves, and it presents the general theory on a basis of fundamental conceptions that have been of essential importance for 
all later work. He showed that a curve of the $n^{\text {th }}$ degree is determined in general by $\frac{1}{2} n(n+3)$ points, and that parallel lines meet any algebraic curve in the same number of real or imaginary points. The determination of asymptotes, straight or curved, and of the manner in which a curve approaches its asymptotes are excellently treated on the basis of expansions. His proof of Newton's Theorems on cubics is also worthy of notice, but the many notable features that distinguish this first fruit of Stirling's genius can not be detailed here. ${ }^{1}$

The work by which Stirling is best known is his Methodus Differentialis-not a treatise on the Differential Calculus as that term is now understood but rather on what we call Finite Differences, though that name is inadequate. The book was published in 1730, and contains (i) an Introduction (pp. 1-13); (ii) Part I, Summation of Series (pp. 15-84); (iii) Part II, Interpolation of Series (pp. 85-153). Mr Tweedie has dealt so fully with the special features of Stirling's work in papers in the Proceedings of the Edinburgh Mathematical Society and in his book on Stirling that it seems unnecessary for me to dwell on them. I would like however to make one remark. If one wishes to get a real insight into the genius of Stirling or of any writer it is absolutely necessary to study the original writings; the too frequent habit of depending on accounts of these writings gives a very imperfect view and it is comparatively uninstructive. It is only by approaching the subject from the standpoint of the writer, and with a knowledge of the limitations prescribed by the state of mathematical science at the time, that the special merits of the writer can be properly estimated. The developments of the Methodus Differentialis have an intimate relation to Gamma Functions and the Hypergeometric Series, but in the study of Stirling we appreciate the genius that enabled him to handle intractable series without the aids that the later developments put at our disposal. It is of course not to be expected that the mathematical student can study at first hand even the majority of the older writers, but I do think that he should make a firsthand acquaintance with some of them; next to Newton I would place Stirling as the man whose work is specially valuable where series are in question. Stirling's work is comparatively small in bulk, and when one had become familiar with the phraseology and manner of statement it would be possible to tackle the bulky

1 For some valuable remarks on Stirling's work on curves I would refer to an article by Wieleitner (Billiotheca Mathematica, Band XIV., 55-62.) 
volumes that comprise the researches of men like Euler whose work is, I fear, more often quoted than read.

During the early years of his residence at Leadhills Stirling found congenial companionship in Colin Maclaurin who was then Professor of Mathematics in Edinburgh University, and to Mr Tweedie we are indebted for a study of Maclaurin's researches that has thrown new light on their importance for the development of geometry, and gives us some insight into his many-sided activities. In what I have to say of Maclaurin I borrow freely from Mr Tweedie's articles, but I hope that all interested in the history of mathematics will have the good sense to study these articles for themselves if they have not already done so. These are

(1) A Study of the Life and Writings of Colin Maclaurin. (Mathematical Gazette. October 1915.)

(2) The "The Geometria Organica" of Colin Maclaurin: A Historical and Critical Survey. (Proc. R.S.E. Vol. 36. Part I (No. 5). 1916.)

Colin Maclaurin was born at Kilmodan in Glendaruel, Argyleshire, in 1698. His father who was minister of the parish died when Colin was only six weeks old, his mother died when he was nine years of age, and the family were taken in charge by an uncle, Daniel Maclaurin, minister of Kilfinnan, who faithfully discharged his duty to them. At the age of eleven Colin was sent to Glasgow University and placed under the charge of Gerschom Carmichael, Regent, afterwards Professor of Moral Philosophy, with a view to the ministry of the Scottish Church. It is reported however that when but twelve years of age he fell in with Euclid's Elements, was fascinated by the subject, and in a few days mastered the first six books. He got into touch with Simson and, under his guidance, set himself to the serious study of mathematics. Though Maclaurin, fortunately for the progress of mathematics, diverged into lines of research that were alien to Simson's bent he always maintained a warm respect for his old professor-in spite of the fact that he in later years, not quite justly I think, gave vent to the expression that Simson was "lazy."

In 1717 he was chosen, after a ten days' competitive examination, Professor of Mathematics in Marischal College, Aberdeen. Shortly after his appointment he contributed two papers to the Philosophical Transactions the substance of which was incorporated 
in the Geometria Organica which appeared in 1720, Newton's Imprimatur being dated Nov. 12, 1719. The somewhat slack conditions that were apt to show themselves in the Scottish Universities of that period are exemplified in the fact that in 1722 Maclaurin acted as tutor to a son of Lord Polwarth during a visit to the Continent; the visit lasted till the end of 1724, when Maclaurin returned to Aberdeen to resume the professorial duties for which he had apparently made no provision during his absence. Not unnaturally the College authorities felt aggrieved at his conduct, but possibly the fact that Maclaurin had while in France been awarded a prize by the Académie Royale des Sciences of Paris for his thesis on the Percussion of Bodies (1724) helped to effect a reconciliation. It was a happy circumstance however that he was freed from the difficulties of the position by his appointment in 1725, on the recommendation of Newton, to the Chair of Mathematics in Edinburgh University.

All the accounts that have been handed down of Maclaurin's work in Edinburgh show him to have been a man of lofty ideals and generous outlook, combined with untiring energy and business capacity. The programme of his classes for a session is published in the Scots Magazine for August 1741, and it seems proper to reproduce it as an indication of the state of mathematics under his regime. "He gives every year three Colleges; and sometimes a fourth, upon such of the abstruse parts of the Science as are not explained in the former three. In the first he begins with demonstrating the grounds of vulgar and decimal arithmetic; then proceeds to Euclid; and after explaining the first six books, with the plane trigonometry and use of the tables of logarithms, sines, etc., he insists on surveying, fortification and other practical parts and concludes this college with the elements of algebra. He gives geographical lectures, once in a fortnight, to this class of students.

In the second college he repeats the algebra again from its principles and advances further in it; then proceeds to the theory and mensuration of solids, the spherical trigonometry, the doctrine of the sphere, dialling and other practical parts. After this he gives the doctrine of the conic sections, with the theory of gunnery, and concludes this college with the elements of astronomy and optics.

He begins the third college with perspective; then treats more fully of the astronomy and optics. Afterwards he prelects on Sir Isaac Newton's Principia and explains the direct and inverse 
method of fluxions. At a separate hour he begins a college of experimental philosophy, about the middle of December, which continues thrice every week till the beginning of April; and at proper hours of the night describes the constellations and shews the planets by telescopes of various kinds."

Even though the academical year was only from the lst of November to the end of May the strain implied by this course must have been severe; in one letter to Stirling he speaks of "teaching six hours daily," and in another "I have so much drudgery in teaching that I am commonly so fatigued at night I can do little business." Added to the heavy official duties were the calls which his popularity in the social circles of the city made on his leisure.

He was a man of many interests. The establishment of an astronomical observatory, the proposals for more accurate surveys of the northern coast of Scotland, the subject of Arctic Expeditions, memoirs on the proper gauging of vessels for the use of the Excise, calculations for the basis of a Pension Fund for the widows of ministers and of professors, all claimed and received his attention. His devotion to the general interests of the city was specially manifested during the "forty-five," but his efforts to stimulate the civic authorities to put Edinburgh in a state of defence were unsuccessful, and he had to leave the city. He found a refuge with Dr Herring, Archbishop of York, but his health, never robust, was so much impaired by the hardships he encountered in his flight that he returned to Edinburgh to die. He passed away on the 14th of June 1746 and was buried in the Greyfriars' Churchyard.

In estimating Maclaurin's place in the history of mathematics we should, I think, interpret the word "history" in a wide sense. From one point of view additions to mathematical knowledge by memoirs that embody the results of original research must take the first place; on the other hand research alone is not sufficient to make mathematics a living subject. The stimulus that comes from a capable and enthusiastic teacher is of the highest value in creating a suitable atmosphere as well as in providing the supply of competent workers. The original contributions made by Maclaurin during the twenty years of his Edinburgh professorship are not numerous though they are valuable, but his work as a teacher and administrator had a far-reaching influence on the position of mathematics as an essential element in general culture, and the fact that he took such pains 
with his classes in preparing suitable courses seems to me to indicate that he was alive to the importance of this aspect of his work.

Maclaurin's Account of Newton's Philosophical Discoveries, his Physical and Literary Essays, and his work on mathematical physics - some of it of great value-I can do nothing more than mention. From the standpoint of pure mathematics the important contributions are his Geometria Organica of 1720, his Treatise of Fluxions, published in 1742, and the Treatise on Algebra, with the valuable Appendix on the General Properties of Geometrical Lines which was issued in 1748 after his death.

The Geometria Organica has been subjected to a most careful and exhaustive analysis by $\mathrm{Mr}$ Tweedie, and the main result of Mr Tweedie's investigations has been to prove that Maclaurin's treatise has been strangely neglected and that in this work he has anticipated many of the discoveries of a much later date. It is quite impossible in a short note to summarise the contents of the treatise, but it may be pointed out that many of the well-known properties of Circular Cubics are due to Maclaurin, that the whole theory of Pedals, and more particularly of the Pedals of the Conic Section is given in the Geometria Organica, and that he discovered "a whole host of new curves never before discussed and which have since have been named and investigated with but scant acknowledgment of their true inventor." Regarding the work as a whole $\mathrm{Mr}$ Tweedie thus characterises it. After noting that Maclaurin's use of the Cartesian geometry is, as compared with modern developments, somewhat cumbersome he emphasizes the "consummate skill" with which Maclaurin applies the methods of the ancient geometry. Of the two Parts into which the treatise is divided the first treats the cases in which the loci along which the vertices of constant angles are made to move are straight lines. In the second Part the curves so found in the first Part are added to the loci to obtain curves of higher order. It contains in particular the theory of pedals and the epicycloidal generation of curves by rolling one curve on a congruent curve. The last section contains some general theorems in curves forming the foundation of the theory of Higher Plane Curves. It also contains what is erroneously termed Cramer's Paradox; in fact Cramer quotes Maclaurin as his authority.

The Treatise of Fluxions had its origin in the desire of Maclaurin to defend the Newtonian doctrine of fluxions against Berkeley's attack 
in his essay The Analyst. As he proceeded with the work however he was induced, for various reasons, to expand it into a treatise that would contain an account of all the more important applications of fluxions so that it grew into a bulky volume of over 760 pages. As an exposition of the validity of the theory of limits, and of the fallacies in Berkeley's statement, the discussion is thoroughly sound. After an interesting introduction in which he reviews the methods of exhaustion of the Greek geometers and the method of indivisibles of Cavelleriusan exposition marked by accuracy and breadth of view-he proceeds in Book I to explain and develope the general theory, making use of the conception of a velocity and keeping algebraic symbolism and calculation as far as possible in the background. The range covered is very wide; many of the theorems, for example, respecting areas can be easily interpreted as theorems in integration: his test for the convergence of a series (pp. 289 et seq.) is a case in point. The disadvantages however of the plan on which the treatise is written make themselves felt when in Book II he comes to deal with the Computations in the Method of Fluxions. The proofs of various theorems have either to be repeated from Book I or to be merely sketched, with reference to Book I for complete demonstration. It is interesting to note that he puts the method of infinitesimals on a sound basis, and in fact develops in a rigorous way the theory of differentials; I have no doubt at all that Cauchy's definition of the differential was fully and consciously given by Robins and Maclaurin. Maclaurin also points out (p. 578) that there is no necessity for the introduction of the notion of the generation of quantities by motion, and one has the feeling that much would have been gained by a frank adoption of the Leibnizian and Bernoullian notation for differentials and integrals. The Treatise, in spite of the handicaps imposed, partly by the limited scope which it was at first designed to serve, and partly by too rigid adherence to fluxional notations, is a great storehouse of theorems and applications; the investigations in attractions, the Euler-Maclaurin Summation Theorem and the special form of Taylor's theorem that goes by Maclaurin's name are frequently quoted, but these give only a slight indication of the wealth of results and of the quite exceptional rigour (for the day) of the demonstrations of fundamental theorems.

The Treatise on Algebra was published after his death and gives clear proof of his aptitude as a teacher. It passed through many editions and, while a good commentary on Newton's Arithmetica 
Universalis, it can hold its own as an excellent introduction to the subject-as that subject was understood by the best mathematicians of his time.

It would be out of place to pass from Maclaurin without referring to another instance of his many sided activity. In 1731 a Society had been formed in Edinburgh for the promotion of medical knowledge by collecting and publishing Essays on medical subjects, and had proved its value by the volumes it produced in a few years. In 1739 , Maclaurin was instrumental in broadening the scope of the Society by the inclusion of Philosophy and Literature; the Society was remodelled, a set of laws and regulations was drawn up, the number of members increased and the title of "The Philosophical Society of Edinburgh" adopted, Maclaurin being one of the Secretaries. He took an active part in the work of the new Society and contributed papers that were incorporated, according to Murdoch's statement, in the Treatise of Fluxions and in his Account of Newton's Philosophy. After Maclaurin's death, the Society continued in existence though the spark of life was nearly extinguished when, largely owing to the action of Principal Robertson, it was again remodelled and in 1783 took the form of "The Royal Society of Edinburgh." The important part that The Royal Society has played in the development of scientific knowledge in Scotland is too well known to be insisted upon, but it is pleasant to remember that the foundation of the Society is so directly associated with the activities of Colin Maclaurin. It may perhaps be added that Stirling's name occurs in the List of Original Members of the remodelled Society of 1739 .

On the death of Maclaurin it is stated by Sir Alexander Grant (Story of the Univ. of Edin. II., p. 301) that the patrons desired to appoint Stirling to the Chair but that "his Jacobite principles led him to reject the offered appointment." I am not aware of the authority on which this statement is based, and it would be interesting to have it verified, if correct. In any case Stirling was not appointed and the succession fell to Matthew Stewart.

Matthew Stewart was born at Rothesay in 1717. He entered the University of Glasgow in 1734 and in 1741 went to the University of Edinburgh to prepare for entering the Church. He attended the lectures of Maclaurin during Session 1742-3, was licensed for the Ministry and presented to the living of Roseneath in 1745 . He became a candidate for the Chair rendered vacant by Maclaurin's death and, as an aid to his candidature, issued his book Some General. 
Theorems of considerable use in the Higher Parts of Mathematics. In 1747 he was elected to the Chair and discharged its duties till 1772 when his health gave way. His son Dugald undertook to lecture in his stead and in 1775 was appointed joint-professor. Matthew Stewart died on 23rd January 1785.

Besides the General Theorems, Stewart published in 1761 Tracts, Physical and Mathematical and in 1763 Propositiones Geometricae more Veterum Demonstratae.

Among the General Theorems is one which is of considerable importance and which is now known as Stewart's Theorem. It is a curious fact, however, that the credit for the Theorem is due to Simson; for a full discussion of the matter I would refer to Dr Mackay's paper on "Matthew Stewart's Theorem" in the 10th volume of the Proceedings of the Edinburgh Mathematical Society. There are some strange freaks in the nomenclature of theorems; thus the "Simson Line" is not due to Simson nor "Stewart's Theorem" to Stewart. Except as the man whose name is given to a theorem that occurs in elementary geometry, I doubt if Stewart is at all known or has exercised any important influence on the progress of mathematics. His position seems to me to be fairly stated in the following passage from Chrystal's (unpublished) Inaugural Address (Grant's Story of Univ. of Edin. II. 301). "Though a genius of much lower order than Maclaurin he was nevertheless in his own field an able and original Mathematician. He had been trained by Dr Simson at Glasgow and had imbibed the severe taste of that celebrated expert in the Ancient Geometry. In the cultivation of the Geometrical Analysis of the Ancients Stewart was most successful, and his General Theorems remain much admired monuments of his skill. Like his master Simson he was jealous of the encroachments that Algebra was making on Geometry, and it was his constant aim to reduce to the level of ordinary Geometry problems that were supposed to require the higher calculus. With this view he wrote his Tracts, Physical and Mathematical in which he essayed the application of his pure Geometry to Physical questions. He undoubtedly obtained many important successes in this way; his solution of Kepler's problem being one of the most remarkable. On the whole, however, it was unfortunate for the progress of science in Scotland, that a man of Stewart's limited range should have succeeded the versatile Maclaurin."

Maclaurin's successor in the Chair of Mathematics at the Marischal College, Aberdeen, was John Stewart, whose tenure lasted 
till 1766, a period of nearly forty years. Stewart had graduated in 1726 so that his promotion came to him early in life. Of his general character and work I can find little information; he was a son of a provost of Aberdeen, and seems to have been known among the students by the nickname "John Triangles." His death is recorded in the Scots Magazine, vol. 28, p. 167, and the circumstances of it are rather painful as his wife and eldest daughter died in the same week and, in the words of the notice, "the three corpses were carried to the grave together."

Stewart published in London in 1745 a translation, with elaborate commentary, of Newton's Quadrature of Curves and Analysis by equations of an infinite number of Terms. Naturally Stewart had his fling at Berkeley who would not, I think, have been greatly discomposed by his arguments; still the commentary is a very careful bit of work and would be of real advantage to his more thoughtful students. The difference between Stewart's commentary and Maclaurin's Treatise of Fluxions is however very striking; Maclaurin's is the work of an original thinker, thoroughly versed in the writings of his predecessors and extending their results in many directions, while Stewart is content with explaining in minute detail the text of Newton and rarely ventures to go beyond the text. At the same time I should be disposed to conclude that Stewart must have had a good influence on the University teaching, and have contributed materially to the production of the intelligent group of teachers of mathematics who seem to me to have done excellent work in the eighteenth century.

My narrative now brings me to a man who has been styled "the last of the Fathers of Scottish Science." I wonder how many of you can say who he is and who so characterised him. The man is William Trail, and his sponsor is Sir David Brewster who dedicates his edition of Professor Robison's System of Mechanical Philosophy to Trail, "the last of the Fathers of Scottish Science," and a fellowstudent of Robison "whose talents and virtues he admired."

Trail had been a student of Marischal College in 1759-63, had then come to Glasgow where he took the M.A. degree in 1766, and had formed a close intimacy with Simson which continued till Simson's death. In 1766 he was successful in the competition for the Chair of Mathematics at Marischal College, though Playfair and Robert Hamilton were also candidates. He resigned the professor- 
ship in 1779 on obtaining preferment in the Irish Church and enjoyed his clerical offices for upwards of fifty years, dying at Bath in 1831 at the age of 85 .

It has been said of Trail that he was "a man of great capacity for science, entirely extinguished, together with his taste for its pursuits (as Professor Playfair used to lament) by the sinecure emoluments of the Irish Church."

While in Aberdeen he published Elements of Algebra for the use of Students in Universities. The edition I possess is dated 1789, but it contains an Advertisement, dated Aberdeen, April 1, 1778, stating that it was drawn up for the use of students who were to attend the Lectures of the author, and was not intended to supersede the perusal of a more complete system of Algebra. The book does not bear Trail's name as the author but there is no doubt as to the authorship. Of the book itself little need be said; it is slight but the various operations are clearly described, and the applications of algebra to geometry are on the lines usually followed at that time; in some respects there would be an advantage if our modern school textbooks followed the 18th century books more closely.

Trail's claim to remembrance however depends solely on his Life of Simson. As a biography the book is extraordinarily bad, but it does give a great deal of information about Simson and his geometrical studies that is to be had nowhere else. From an examination of Simson's Adversaria, now in the Glasgow University Library, I can testify how diligently Trail must have studied them; there are some things of interest that he has not transferred to the Life but they are not important, though useful as throwing light on Simson's manner of work. Occasionally letters are given in the Adversaria, not hitherto published, but $\mathrm{I}$ doubt if they are worth putting into print.

The period to which this sketch is limited is now at its close. With the accession of Playfair in 1785 to the Chair of Mathematics in Edinburgh there is the beginning of a decided change in the mathematical outlook. Neither Playfair nor Leslie, his successor in 1805 in the mathematical professorship, can be said to have made contributions of marked importance in the development of mathematics, but both were men of great ability and keenly interested in the advance of mathematical and physical science. Playfair in particular was widely read in the history of mathematics, was in spite of (perhaps it 
would be more appropriate to say "because of") his great admiration for Newton, disappointed with the neglect by contemporary mathematicians in England of the great advances that were being made on the Continent, and set himself "to diffuse among his countrymen a knowledge of the progress which science had been making abroad." (Chrystal in Grant's Story of Edin. Univ. Vol. 2, p. 302.) His Dissertation on the Progress of Mathematical and Physical Science since the Revival of Letters in Europe, contributed to the 4th and later editions of the Encyclopaedia Britannica, is, as respects the mathematical sections at least, a remarkably able and accurate narrative for the time at which it was written. Even the disastrous controversy over the rise of the Calculus is handled with a freedom from prejudice that is a sure guarantee of the genuine scientific spirit; it is, I think (with the possible exception of Maclaurin's Fluxions), the first direct statement in English of the essential elements in the case that is free from a decidedly national bias. He rendered great service to the Royal Society in its early days, being General Secretary for many years, and his Obituary Notices of Matthew Stewart, Hutton and Robison are still frequently cited. His Elements of Euclid was long in use in Scottish Schools; in it he uses the Parallel Axiom now known by his name, though he expressly states that it had been "assumed by others, particularly by Ludlam in his very useful little tract entitled Rudiments of Mathematics" (p. 439 of the 7th Ed.). His article on Porisms in the 3rd vol. of the Transactions is one of the frequently quoted expositions of that much debated subject. In his efforts to broaden the outlook of mathematicians and to arouse an interest in the historical development of science he had an able colleague in Leslie who, though less balanced and more prejudiced in his judgments, deserves to be gratefully remembered for his interest in the philosophical treatment of the elements of mathematics. It is perhaps worth noting that Leslie's Elements of Geometry was translated into French and German, and had for some years a considerable circulation on the Continent. There can be no doubt, I think, that in the closing years of the 18th and the early years of the 19th century, Edinburgh was pre-eminent in Scotland for its active and enlightened interest in science, and the Royal Society was the centre from which that interest was maintained. As an indication of the sympathetic and broadminded spirit of Playfair, the Secretary, it may not be out of place to note that it was through his good offices that the first contributions of Wallace, Leslie's successor in the Chair of Mathe- 
matics, and of James Ivory, afterwards known for his work on the attraction of ellipsoids, appeared in the 4 th volume of the Transactions of the Society. Both men owed much to Playfair's kindly interest, and they justified it by their subsequent contributions to mathematical learning.

Of the position during the closing years of the 18th century in the other Universities there is not much of direct interest to record. So far as I can learn the University Chairs were occupied by men who had a competent knowledge of mathematics and who conducted the normal courses with fair efficiency; but I fear that in more than one University too much energy was devoted to what may be euphemistically called "University administration." Financial difficulties pressed heavily, and the atmosphere in which the professors worked was often very unfavourable to that wholehearted devotion to learning which is necessary for its steady progress. At the same time it is, I think, the case that advance was being made and that the level of attainment was fairly high; up and down the country, schools were to be found whose mathematical curriculum included conic sections and elementary calculus, and the presence of such schools, even though not in every town, indicates a provision of teachers and an outlook for their pupils that could only be met by the Universities.

In this very imperfect sketch $I$ have confined myself almost exclusively to the Universities; I have done so chiefly for the lack of material that could be presented in a sufficiently definite form. De Morgan has made the remark (Arithmetical Books, p. vi) "It is essential to true history that the minor and secondary phenomena of the progress of mind should be more carefully examined than they have been. ... Copernicus and Newton would fill a large space, though the history of knowledge were written down to that of every individual who ever opened a book: but it seems to me that they and their peers are made to fill all the space. Nor will it be otherwise until the historian has at his command a readier access to second and third rate works in large numbers; so that he may write upon effects as well as causes." I cordially agree with De Morgan in this attitude. The historian of mathematics should know not merely the work of the pioneers but the extent to which mathematics permeates the community, and the history is shorn of much of its value if it pay little or no attention to the humbler exponents through whom the subject is brought to bear upon the general 
culture of the citizen. I would suggest therefore as a research that would be of distinct value an enquiry into the curricula and textbooks of the schools during the period I have been dealing with. So far as I am aware there is no satisfactory account of such matters in existence. There is one textbook of Arithmetic whose fortunes have been traced with some success and that is Gray's Arithmetic, on which Mr Tweedie contributed a most interesting article to the Proceedings of our Society (vol. 43, pp. 70-80, 1924). Research on the lines indicated by Mr Tweedie seems to me to be called for, and is surely within the compass of our members. It would not demand a wide knowledge of modern developments but it would call for patience and industry; above all it would need to be based on actual inspection of books and not on secondhand statements about books. Probably no one University would provide specimens of all books reported to exist; many even may have completely disappeared-the special fate of the early editions of popular school books; but in the four University Libraries and in Public Libraries there are probably many textbooks whose existence is apparently unknown.

The following list of books that I have seen and turned over, though not thoroughly examined, except in a few cases, may be noted.

On Arithmetic or Arithmetic and Algebra.

Tyrocinia Mathematica. By George Sinclair. Glasgow, 1661.

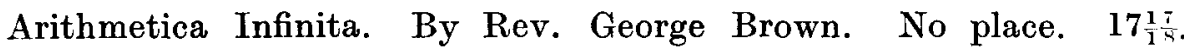
A set of tables of decimals of a $£$, multiples of the farthing.

A new System of Arithmetic, both theoretical and practical. By Alexander Malcolm. London 1730.

Malcolm was a graduate of Marischal College, Aberdeen, and this book is of quite striking merit. He was a teacher and writing master in Aberdeen; eventually he made his way to America where he died in 1763.

Arithmetic, Rational and Practical. By John Mair. The edition I have seen is the 5th. Edin. 1794.

Mair was rector of Perth Academy, and the author of several textbooks for schools; that on Bookkeeping ran through several editions. 
Introduction to Arithmetick. By John Wilson, A.L.M. Teacher of Mathematics and consequently Navigation. Edinburgh, 1741.

A Short System of Arithmetic and Bookkeeping. By Robert Hamilton. London: 1788.

Hamilton was Professor of Mathematics in Marischal College. A much more important book is his

Introduction to Merchandize. It ran through several editions, the first (which I have not seen) being published at Edinburgh in 1777. The copy I possess is a later edition, "new-modelled and adapted to the improved methods and information of the present time." By Elias Johnston, Teacher of Mathematics in Edinburgh. Hamilton is much better known through his work in Political Economy. His Inquiry concerning the Rise and Progress, the Redemption and Present State of the National Debt of Great Britain, published in 1813, made a very considerable name for him in political circles.

The Practical Figurer or an Improved System of Arithmetic. By William Halbert. Paisley: 1789.

Halbert was schoolmaster at Auchinleck; the book has a portentously long title. Of no special merit; pretentious.

The Young Ladies Arithmetic. By John Greig. 2nd Ed. Lond. 1800 .

Greig was a graduate of Marischal College; the book is stated to have gone through many editions.

The school books on Arithmetic by Gray and Melrose went through many editions; Melrose's was edited, in the later issues, by Ingram and Trotter. A study of Melrose on the lines on which Mr Tweedie treated Gray would, I think, show a remarkable longevity.

There are probably many books besides these which $I$ have not seen. The schoolbooks on Geometry are almost limited to editions of Euclid, based on Simson, such as Playfair's and Ingram's-both excellent books. To the texts of Euclid was frequently appended a short textbook of Trigonometry, both Plane and Spherical; I possess issues of Simson, Playfair and Ingram which contain such Appendices. No doubt many of these would be for University use, but certainly not all. 
Translations of Simson's Conic Sections, chiefly the first three books, seem to have been frequently used; an edition I possess is "a new and revised edition," issued at Glasgow in 1817. The Elements of Conic Sections, by Richard Jack, Teacher of Mathematicks in Edinburgh (Edin. 1742) owes a good deal to Simson's Conics.

A separate book on Trigonometry, with the title Elements of Trigonometry, plane and spherical; with the Principles of Perspective and Projection of the Sphere, by John Wright, was published at Edinburgh in 1772 .

Perhaps the most characteristic type of book on mathematics is that represented by the well known works of John Davidson, Alexander Ingram, and, though less known, Alexander Ewing. Of the personal history of these men I know little. Davidson was a teacher in Burntisland, Ingram and Ewing in Edinburgh; I think Davidson was a schoolmaster, but Ingram and Ewing "private teachers," of whom there seem to have been a considerable number in the University towns. As is well known these books range over the whole field of elementary mathematics and many of its applications. I am old fashioned enough to hold that they were an excellent introduction to mathematics; they were prized in many a village school, were used for the training of the sons of artisans and farmers at a time when the parish was almost self contained, and secured for the schoolmaster a status as a scholar that is not nowadays accorded to an Honours graduate.

This short list could probably be extended very considerably, and I hope that we shall not have long to wait for a thorough investigation of the whole subject.

The old Scottish sermon used to end with an application, just as many of the stories of my boyhood would have been considered incomplete unless they contained a moral. I can not end without suggesting that there is a lesson for us in the history $I$ have so imperfectly sketched. The lesson is this, that we must be careful (i) to preserve a balance in our studies, and (ii) to remember that science is not the peculiar possession of any one nation. (i) I believe that Simson did a great work for sound mathematics in his exposition of the ancient geometry, but his admiration for the ancients prevented him from seeing the value of the analytical methods that were beginning to make their way on the Continent and in England. Much as I admire Simson I cannot but think that he did not make 
the contribution that he was capable of making to the advance of mathematics as a whole; he might have limited his own researches to his chosen field, but he should have been more alive to the importance of introducing his students to the newer disciplines that were transforming the traditional methods. (ii) The other phase of this one-sidedness is the long neglect of the calculus except in its purely Newtonian form. I think it may be held with good ground that Newton's work was better understood and more fruitfully applied on the Continent than in England. The fatal controversy on the relative merits of Newton and Leibniz worked untold mischief in this country; I hope we may learn the lesson which just at present there may be a danger of neglecting. 